\title{
Pharmacokinetics of Desflurane in Clinical Setting: At Two Different Flow Rate
}

\author{
${ }^{1}$ Meenoti P Potdar, ${ }^{2}$ Laxmi L Kamat, ${ }^{3}$ Zakera Mahevi
}

\begin{abstract}
Introduction: Desflurane due to its favorable quality of quick wash in and wash out has gained popularity as a preferred inhalational anesthetic agent for low flow anesthesia (LFA) which can be costeffective, minimizing the operation theatre pollution. This study was conducted to assess the pharmacokinetic effects and safety of desflurane in lower flow rates.
\end{abstract}

Aim: To compare the pharmacokinetics of desflurane by assessing its inspired and end tidal concentrations at fresh gas flow (FGF) of 1 and $1.5 \mathrm{~L} / \mathrm{min}$.

To compare the inspired and end tidal concentrations of oxygen, nitrous oxide at 1 and $1.5 \mathrm{~L} / \mathrm{min}$ FGF, to assess the safety as per adequate oxygenation and depth of anesthesia, haemodynamic stability, consumption of gases, MAC values and incidence of awareness.

Materials and methods: One hundred patients were included and divided into two groups of 50 each of ASA grades I and II undergoing general anesthesia for laparoscopic abdominal surgeries. They were maintained with FGF of group $A-1 \mathrm{~L} / \mathrm{min}$, group $\mathrm{B}-1.5 \mathrm{~L} / \mathrm{min}$

All patients were monitored for hemodynamics, entropy, inspired and expired concentration of desflurane, oxygen, nitrous oxide, MAC values at FGF depending on the group with $\mathrm{O}_{2}: \mathrm{N}_{2} \mathrm{O} 50: 50$ and $5 \%$ desflurane. The recovery parameters, side effects and awareness were noted.

Results: We found that Inspired and end tidal concentrations of desflurane were significantly different for both groups, but the difference between inspired and end tidal concentrations and ratio of end tidal to vaporizer setting were comparable as the duration of anesthesia increases suggesting saturation being achieved. The inspired and end tidal concentrations of oxygen were significantly different but were maintained at adequately safe levels. Hemodynamics were maintained and comparable in both the groups. The MAC values and requirements of desflurane, oxygen and nitrous oxide were higher in group $B$ and recovery took significantly longer time. The incidence of side effects were comparable and none of the patients experienced awareness.

\footnotetext{
${ }^{1}$ Consultant Anesthesiologist, ${ }^{2}$ Ex-HOD, ${ }^{3}$ Senior Resident

${ }^{1-3}$ Department of Anesthesia, Dr. LH Hiranandani Hospital, Mumbai, Maharashtra, India
}

Corresponding Author: Meenoti P Potdar, Consultant Anesthesiologist, Department of Anesthesia, Dr. LH Hiranandani Hospital, Mumbai, Maharashtra, India, e-mail: meenoti@yahoo.com
Conclusion: The pharmacokinetics of desflurane favour the use of LFA. Conducting anaesthesia at a FGF $1 \mathrm{~L} / \mathrm{min}$ was equally safe and there was no added advantage of using $1.5 \mathrm{~L} / \mathrm{min}$ FGF. In today's modern era low flow anesthesia can be safely practiced and reduces the cost and environmental pollution.

Clinical significance: Desflurane can be used efficiently at lower rates with the advantage of reducing the cost and not jeopardising the safety as per the oxygenation, hemodynamic stability and depth of anesthesia.

Keywords: Desflurane, Expired, Inspired, Pharmacokinetics.

How to cite this article: Potdar MP, Kamat LL, Mahevi Z. Pharmacokinetics of Desflurane in Clinical Setting: At Two Different Flow Rate. Res Inno in Anesth 2018;3(2):41-53.

\section{Source of support: Nil}

\section{Conflict of interest: None}

\section{INTRODUCTION}

Desflurane $^{1,2}$ is a polyfluorinated methyl ethyl ether compound that is identical in chemical structure to isoflurane except for the substitution of fluoride for chloride ion at the $\alpha$ ethyl carbon. This substitution of single atom radically alters its physical properties in comparison to the other ether anesthetics. The extensive fluorination and molecular symmetry of this anesthetic renders it resistant to microsomal enzyme systems and hydrolysis in soda-lime absorbers. It has very low blood and tissue solubility. These characteristics distinguish desflurane from the remainder of the halogenated ether inhalational anesthetics. It has low blood/gas (0.42) and oil/gas (18.7) partition coefficients ${ }^{1}$ as compared to the other potent inhalational agents. These indicate that it will undergo rapid wash in and washout (and hence, rapid induction and recovery from anesthesia) and have a MAC value of about $6.6 \%$. ${ }^{1,3}$

The low flow anesthesia (LFA) has gained popularity over the years, due to economic concerns, environmental factors, advances in monitoring and introduction of new expensive anesthetics. LFA is carried out with a fresh gas flow (FGF) rate which is significantly lower than the minute volume. When such low FGF are used, the anesthetic gases must be conducted to the patient via closed rebreathing systems. The rebreathing fraction increases with the reduction of the fresh gas flow whereas the volume of excess gas decreases. 
Lower FGF rates provide more cost saving, efficacious and ecologically improved method of anesthesia. Besides, it also improves temperature and humidity of anesthetic gases.

This study was conducted to assess the pharmacokinetic effects and safety of desflurane in lower flow rates.

\section{AIMS AND OBJECTIVES}

- To study and compare the pharmacokinetics of desflurane by assessing the inspired and end tidal concentrations of desflurane at FGF of $1.5 \mathrm{~L} / \mathrm{min}$ and $1 \mathrm{~L} / \mathrm{min}$.

- To compare the inspired and end tidal concentrations of oxygen, nitrous oxide and carbon dioxide at FGF of $1.5 \mathrm{~L} / \mathrm{min}$ and $1 \mathrm{~L} / \mathrm{min}$ and to assess the safety as per adequate oxygenation and depth of anesthesia.

- To assess the hemodynamic stability with different flow rates.

- To assess the consumption of desflurane with both flow rates

- To compare the MAC values achieved at different flow rates.

- To assess the incidence of postoperative sedation, pain, nausea, vomiting and awareness with use of desflurane at 1 and $1.5 \mathrm{~L} / \mathrm{min}$

\section{MATERIALS AND METHODS}

It was hospital based prospective randomized single blinded comparative study. The study was carried out on the 100 patients of Dr LH Hiranandani Hospital, Powai, Mumbai undergoing laparoscopic abdominal and pelvic surgeries over the period of 1 year (April 2012-2013).

\section{Inclusion Criteria}

Patients with ASA 1 and 2 with age of 18-60 years, weight $<80 \mathrm{kgs}$, height $145-165 \mathrm{cms}$ undergoing general anesthesia (GA) for abdominal and pelvic laparoscopic surgeries, lasting approximately 60 minutes till 180 minutes, with valid consent were included in the study.

\section{Exclusion Criteria}

Patients undergoing emergency surgeries, allergic to anesthetics agents, on medications with hemodynamic effect, pregnant women, with neuromuscular diseases, having epidural analgesia catheter and posted for day care surgeries were excluded out of the study.

The sample size was calculated as per pilot study conducted on 25 patients in each group. Considering significance level (alpha level) of 0.05, assuming the arithmetic mean difference of end tidal concentrations of desflurane in both groups as 0.15 and standard deviation of 0.22 , with a power of $95 \%, 2$ sample T test was applied using Minitab. The sample size calculated was 48 per group. Hence we decided to do 50 patients per group

\section{Methods}

After institutional ethics committee approval and written informed consent, 100 patients of either sex posted for various abdominal surgical procedures were included in the study. After reviewing the pre-anesthetic check-up, airway assessment, baseline investigations, the patients were divided into two groups in a randomized manner. Randomization was done by chit system. Chits numbered from 1-100 were kept in opaque envelopes. All the odd numbers were included in group A, i.e., $1 \mathrm{~L} / \mathrm{min}$ FGF and all even numbers in group B, i.e., $1.5 \mathrm{~L} / \mathrm{min}$ FGF. For each patient fulfilling the inclusion criteria, one envelope was picked and depending upon the odd or even number picked, they were grouped in either groups A or B. Patients, surgeons, and other residents involved in patient assessment and treatment were kept blinded to group assignment.

After checking the consent and confirming the NBM status, patients were wheeled in to operation theatre. They were monitored for heart rate (HR), mean arterial pressure (MAP), peripheral oxygen saturation $\left(\mathrm{SpO}_{2}\right)$, respiratory rate (RR) and entropy. Patients were premedicated with injection glycopyrolate $0.2 \mathrm{mg}$ IV and injection ondansetron $4 \mathrm{mg}$ IV. All the patients were preoxygenated with $100 \% \mathrm{O}_{2}$ for $3 \mathrm{~min}$. Each patient was given injection fentanyl $2 \mathrm{mcg} / \mathrm{kg}$ with injection midazolam 0.02-0.03 $\mathrm{mg} / \mathrm{kg}$ IV bolus. GA was induced with inj. propofol 2 $\mathrm{mg} / \mathrm{kg}$ followed by injection rocuronium $0.6 \mathrm{mg} / \mathrm{kg}$, patients were intubated with cuffed endotracheal tube and connected to closed breathing system. Post intubation FGF was kept at $4 \mathrm{~L} / \mathrm{min}$ with $\mathrm{O}_{2}: \mathrm{N}_{2} \mathrm{O}$ as 50:50. Desflurane vaporizer was set at $5 \%$ in both groups. This initial phase of high FGF lasted till end expiratory concentration of desflurane is equal to $0.8 \times \mathrm{MAC}$. After this, flow rates were reduced to $1 \mathrm{~L} / \mathrm{min}$ in group $\mathrm{A}$ and to 1.5 $\mathrm{L} / \mathrm{min}$ in group B. Desflurane dial setting is maintained at $5 \%$ throughout the surgery. At the end of surgery, vaporizer was switched off and patient was given 100\% $\mathrm{O}_{2}$. The FGF was increased to $4 \mathrm{lit} / \mathrm{min}$.

During intraoperative period, patients were monitored for $\mathrm{HR}, \mathrm{SBP}, \mathrm{DBP}, \mathrm{MAP}$, and $\mathrm{SpO}_{2}$. Inspired and expired concentrations of $\mathrm{O}_{2}, \mathrm{CO}_{2}, \mathrm{~N}_{2} \mathrm{O}$ and desflurane are noted along with entropy, $\mathrm{MAC}$, tidal volume, minute volume. Time required to achieve entropy of 40-60 and MAC of 0.8 was noted. Time needed to achieve decrease in end expiratory concentration of desflurane (EtDes) by $<50 \%$ was noted at the end of surgery. Rescue anlgesia is provided with bolus of Inj.Fentanyl $25 \mathrm{mcg}$ IV with increase in $\mathrm{HR} / \mathrm{BP}>20 \%$. Any episode of hypotension was treated 
with adequate IV fluids. In case of any hemodynamic instability, case was excluded from the study. The total amount of $\mathrm{N}_{2} \mathrm{O}$, desflurane and $\mathrm{O}_{2}$ consumption was noted at the end of surgery which was calculated by the software of the anaesthesia machine. Also, time required for spontaneous eye opening, time required to respond to verbal commands, time to achieve entropy of 80-90 and time for extubation was noted. In presence of pain (VAS >3) in recovery room, patients were given injection paracetamol $1 \mathrm{gm}$ IV. Postoperatively patients were assessed for sedation by Ramsay sedation score (RSS).

\section{Ramsay Sedation Scale}

1. Patient is anxious and agitated or restless, or both

2. Patient is cooperative, oriented and tranquil

3. Patient responds to commands only

4. Patient exhibits brisk response to light glabellar tap or loud auditory stimulus

5. Patient exhibits a sluggish response to light glabellar tap or loud auditory stimulus

6. Patient exhibits no response

Postoperative incidence of nausea, vomiting and pain was also noted. Pain was assessed by using visual analog pain scale (VAS) where score of zero corresponded with no pain and score of 10 means intense unbearable pain. Intraoperative awareness will be evaluated postoperatively by questioning the patient on the morning after surgery.

\section{Awareness Assessment Questionnaire}

- What was the last thing you remembered happening before you went to sleep?

- What was the first thing you remembered happening on waking?

- Did you dream or have any other experiences whilst you were sleep?

- What was the worst thing about your operation?

- What was the next worst thing?

\section{OBSERVATIONS AND RESULTS}

The study included 100 patients, 50 in each group. No patient was excluded out of the study.

\section{Statistical Analysis}

The data was managed in Microsoft excel spreadsheet. Demographics and general information like count, average and percentage for various parameters with all permutations and combinations were calculated in Microsoft excel. Demographics are described with average, standard deviation, median. Analysis of variance (ANOVA) one way was used to investigate the impact of various parameters like pulse, SBP, DBP, MAP, MAC, and inspired and end-tidal concentrations of desflurane, oxygen, nitrous oxide and carbon dioxide. A $p$ value $<0.05$ was considered statistically significant. Two sample $t$ test was used to observe the effect of groups on the total amount of desflurane, $\mathrm{N}_{2} \mathrm{O}, \mathrm{O}_{2}$ and fentanyl and the time required for extubation. All statistical analysis was done using Minitab 16.

\section{DEMOGRAPHIC CHARACTERISTIC}

The mean age, height, and weight in both the groups were comparable as shown in Table 1 . In group A had $90 \%$ females and $10 \%$ males, group $\mathrm{B}$ had $78 \%$ females and $22 \%$ males. These difference were comparable by applying Fisher's exact test, $p$ value being 0.171 . In each group 27 patients, i.e., $54 \%$ belonged to ASA 1 and 23 patients, i.e., $46 \%$ were from ASA2 and the distribution being comparable.

\section{Comparison of Inspired Desfurane (InsDes) and End- tidal Desfurane (EtDes) Concentrations: (Table 2)}

In group A (Graph 1), with vaporizer setting of 5\% the mean InsDes at $30 \mathrm{~min}, 60 \mathrm{~min}, 90 \mathrm{~min}$ and $120 \mathrm{~min}$ were $4.05 \pm 0.21,4.22 \pm 0.18,4.25 \pm 0.13,4.28 \pm 0.12$ and in Group B were $4.22 \pm 0.19,4.33 \pm 0.17,4.38 \pm 0.14,4.42 \pm 0.11$ respectively. After applying ANOVA test, $p$ values are $<0.05$ at 30 $(p=0.0001), 60(p=0.003), 90(p=0.002)$ and $120(p=0.008)$ minutes. Thus groups differ significantly.

Similarly, in group A (Graph 2), with vaporizer setting of $5 \%$ the mean EtDes at $30 \mathrm{~min}, 60 \mathrm{~min}, 90 \mathrm{~min}$ and 120 min were $3.64 \pm 0.25,3.89 \pm 0.22,3.99 \pm 0.16,4.05 \pm 0.14$ and in group B were $3.81 \pm 0.22,4 \pm 0.2,4.09 \pm 0.17,4.15 \pm 0.15$ respectively. After applying ANOVA test, $p$ values are

Table 1: Comparison of demographic data in both the groups

\begin{tabular}{|c|c|c|c|c|c|c|}
\hline \multirow[b]{2}{*}{ Demographics } & \multicolumn{3}{|c|}{ Group A } & \multicolumn{3}{|c|}{ Group B } \\
\hline & Mean & $S D$ & Median & Mean & $S D$ & Median \\
\hline Age in year & 40.9 & 12.88 & 38 & 44.12 & 11.51 & 45.5 \\
\hline Weight in $\mathrm{kg}$ & 63.68 & 11.27 & 64.5 & 65.78 & 9.38 & 65 \\
\hline Height in $\mathrm{cm}$ & 156.18 & 5.85 & 156.5 & 157.38 & 5.54 & 158 \\
\hline Duration of surgery in mins & 98.06 & 31.08 & 91.5 & 92.9 & 32.02 & 77.5 \\
\hline \multirow[t]{2}{*}{ Gender } & Male & Female & Total & Male & Female & Total \\
\hline & 5 & 45 & 50 & 11 & 39 & 50 \\
\hline \multirow[t]{2}{*}{$A S A$} & I & II & Total & $I$ & II & Total \\
\hline & 27 & 23 & 50 & 27 & 23 & 50 \\
\hline
\end{tabular}


Table 2: Difference between inspired and end tidal concentrations of desflurane

\begin{tabular}{lllllllll}
\hline & \multicolumn{3}{c}{ Group $A$} \\
\cline { 2 - 9 } FGF & $30 \mathrm{~min}$ & $60 \mathrm{~min}$ & $90 \mathrm{~min}$ & $120 \mathrm{~min}$ & $30 \mathrm{~min}$ & $60 \mathrm{~min}$ & $90 \mathrm{~min}$ & $120 \mathrm{~min}$ \\
\hline InDes & $4.05 \pm 0.21$ & $4.22 \pm 0.18$ & $4.25 \pm 0.13$ & $4.28 \pm 0.12$ & $4.22 \pm 0.19$ & $4.33 \pm 0.17$ & $4.38 \pm 0.14$ & $4.42 \pm 0.11$ \\
EtDes & $3.64 \pm 0.25$ & $3.89 \pm 0.22$ & $3.99 \pm 0.16$ & $4.05 \pm 0.14$ & $3.81 \pm 0.22$ & $4.0 \pm 0.2$ & $4.09 \pm 0.17$ & $4.15 \pm 0.15$ \\
InsDes-EtDes & 0.41 & 0.33 & 0.26 & 0.23 & 0.41 & 0.33 & 0.29 & 0.27 \\
\hline
\end{tabular}

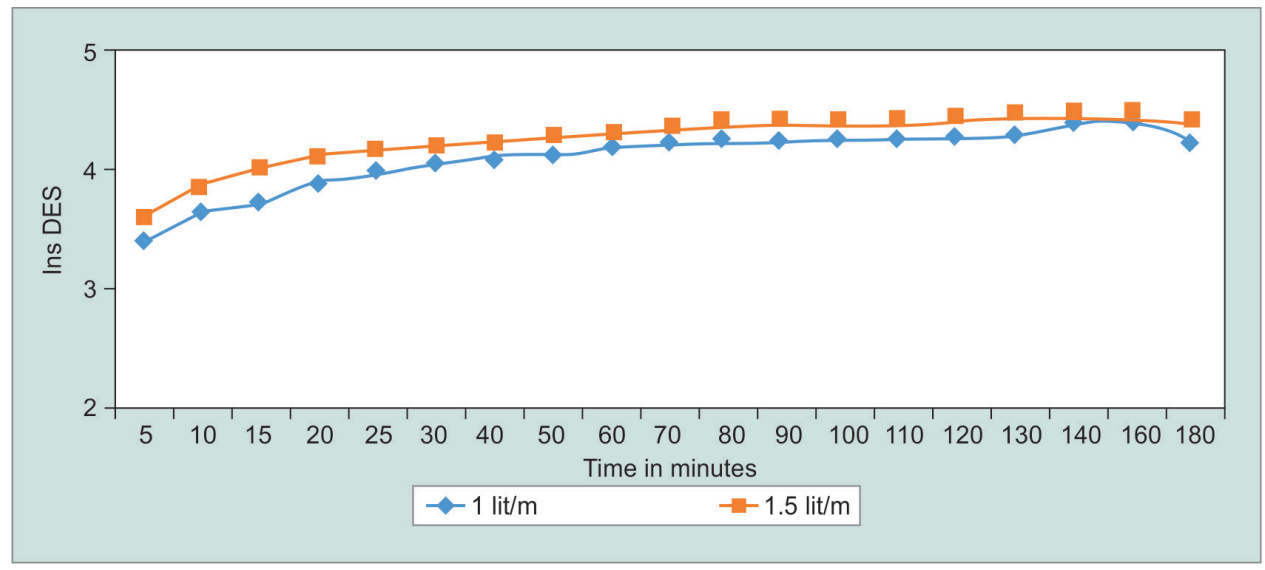

Graph 1: Inspired desflurane concentrations in two groups

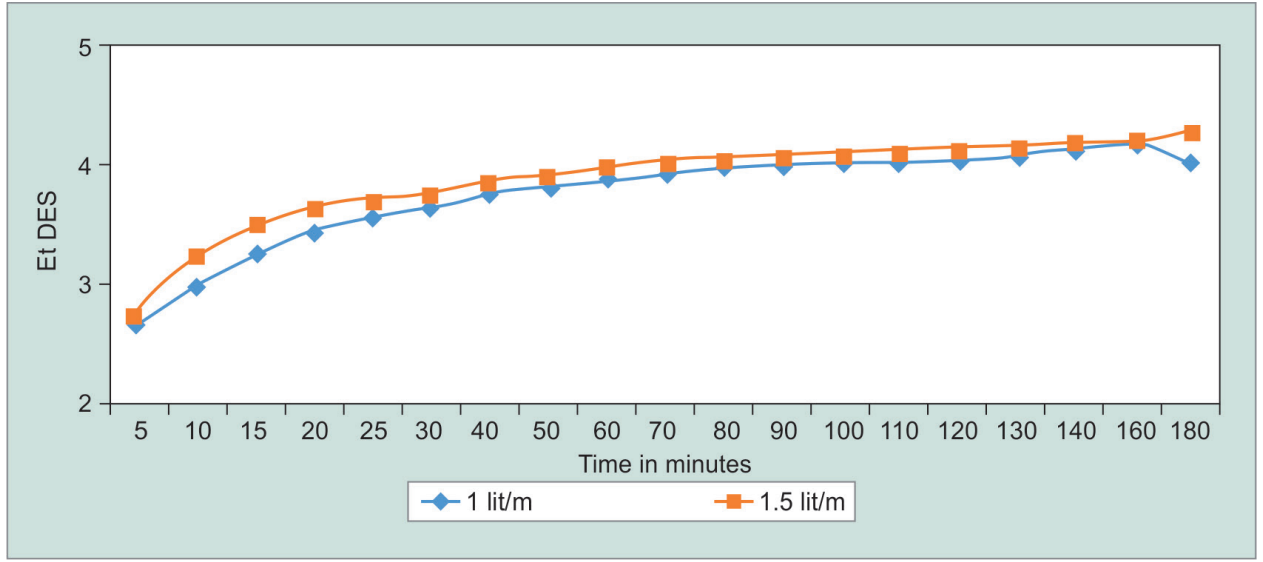

Graph 2: End tidal desflurane concentrations in two groups

$<0.05$ at 30,60 and 90 minutes $(0.0001,0.011,0.05$, respectively), but is $>0.05(0.09)$ at 120 minutes. Thus it was found that both the groups differ significantly at 30,60 and 90 minutes but not at 120 minutes.

\section{Comparison of Difference between Inspired and End-tidal Concentrations of Desflurane}

The difference between InDes and EtDes (Table 2) in group A at 30, 60, 90 and $120 \mathrm{~min}$ were $0.41,0.33,0.26$ and 0.23 . Same for group B were 0.41, 0.33, 0.29 and 0.27. As per one-way ANOVA test $p$ values at 30,60 and 90 minutes are $0.822,0.803,0.069$. At 120 minutes ( 2 sample T test) $p$ value is 0.54 , thus is comparable between both the groups.

\section{Comparison of Ratio of EtDes/InsDes}

Mean value for both the groups is 0.91 at all point times in both the groups is comparable (Graph 3).
Comparison of EtDes at 5\% at 30-60-90-120 min between the groups.

Mean values (Graph 4) for group A at 30, 60, 90 and $120 \mathrm{~min}$ is $0.7284,0.7772,0.7984$ and 0.809 . For group B, mean values are $0.7628,0.7992,0.818$, and 0.83 , which are comparable.

\section{Comparison Within and Between Groups for Inspired Oxygen Concentration (InsO $\left.\mathrm{O}_{2}\right)$}

In group $\mathrm{A}$, the mean $\mathrm{Ins} \mathrm{O}_{2}$ at $30 \mathrm{~min}, 60 \mathrm{~min}, 90 \mathrm{~min}$ and 120 min were $45.24 \pm 1.49,43 \pm 1.21,41.77 \pm 0.99,40.91 \pm$ 1.14 and in Group B were $45.36 \pm 1.03,43.8 \pm 0.99,43.33$ $\pm 1.15,43.08 \pm 1$, respectively (Graph 5 ). At 30 minutes, $p=0.64$ and the groups are comparable. At 60, 90 and 120 minutes $p$ values are $<0.05$ (0.0001). Thus groups differ significantly in inspired $\mathrm{O}_{2}$ levels and there is a fall in the inspired oxygen concentration as the duration 


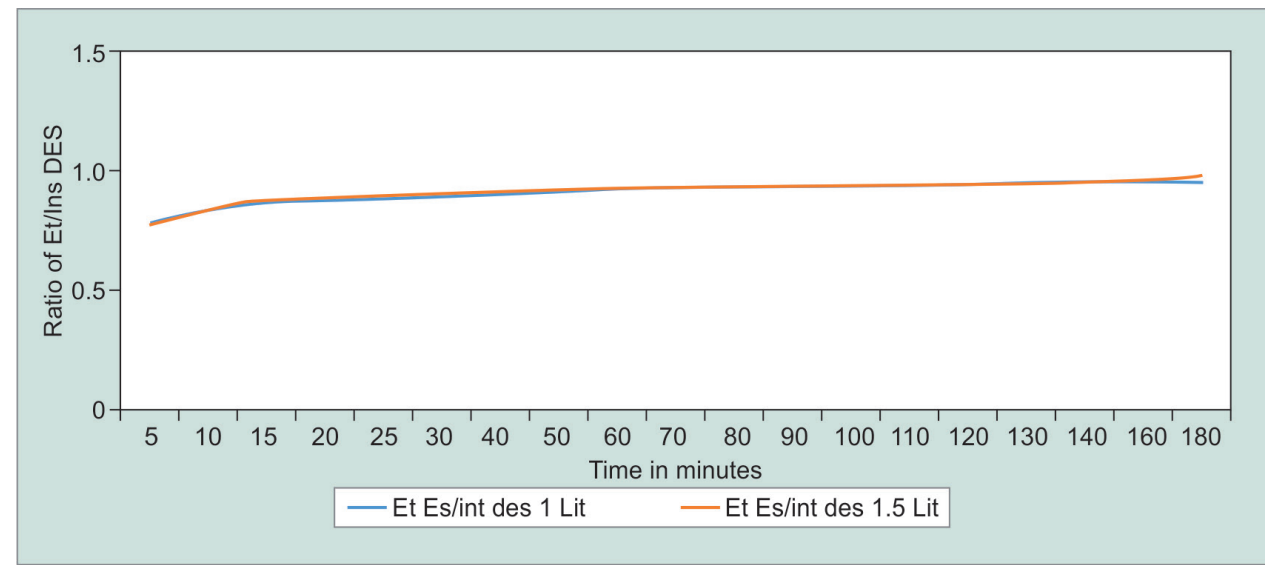

Graph 3: Comparison of ratio EtDes / Ins Des

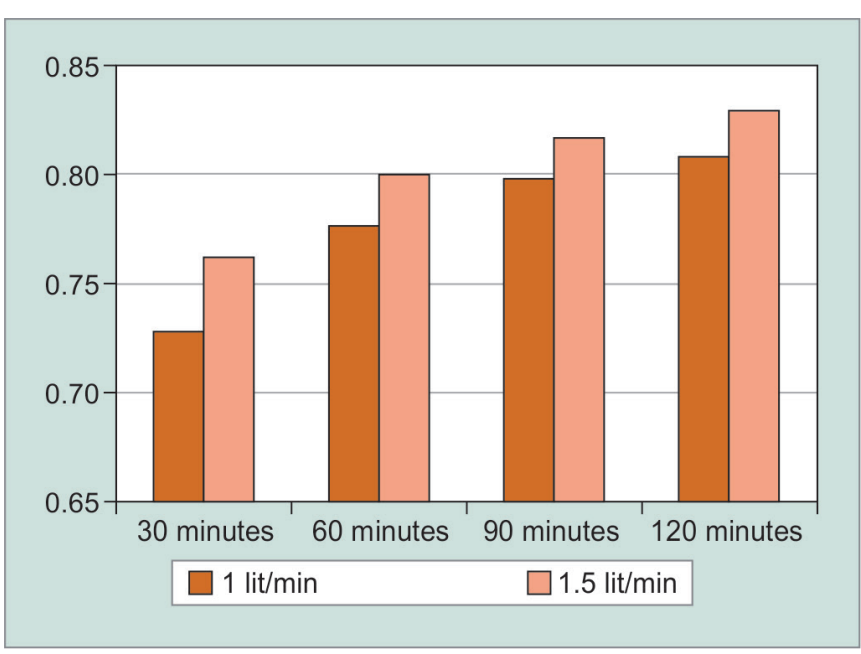

Graph 4: Ratio of EtDes to vaporizer setting

of anesthesia increases. This fall in the oxygen content is more in group A than group B.

\section{Comparison Within and Between Groups for End-tidal Oxygen Concentration $\left(\mathrm{Et}_{2}\right)$}

In group $\mathrm{A}$, the mean $\mathrm{Et}_{2}$ at $30 \mathrm{~min}, 60 \mathrm{~min}, 90 \mathrm{~min}$ and 120 min were $42.98 \pm 1.93,39.86 \pm 1.69,38.31 \pm 1.23,37.09 \pm 1.3$ and in Group B were $42.7 \pm 1.45,40.72 \pm 1.16,39.95 \pm 1.07$, $39.5 \pm 1$, respectively (Graph 6). $p$ value is 0.41 at 30 minutes. Thus there is no significant difference in $\mathrm{Et}_{2}$ levels in both the groups. But at 60, 90 and 120 minutes $p<0.05$ (0.004, 0.0001 , and 0.0001 ) and the groups differ significantly. As the Ins $\mathrm{O}_{2}$ there is a similar fall in the $\mathrm{Et}_{2}$ as the duration of the surgery increases and more in the group $\mathrm{A}$ than group B. The fall in $\mathrm{Et} \mathrm{O} 2$ was never below $30 \%$.

\section{Comparison Within and Between Groups for Inspired Nitrous Oxide (Ins $\mathrm{N}_{2} \mathrm{O}$ ) and Expired Nitrous Oxide $\left(\mathrm{Et}_{2} \mathrm{O}\right)$}

In group A (Graph 7), the mean $\operatorname{InsN}_{2} \mathrm{O}$ at $30 \mathrm{~min}, 60$ $\min , 90 \mathrm{~min}$ and $120 \mathrm{~min}$ were $48.06 \pm 1.81,50.32 \pm 1.53$,
$51.19 \pm 1.55,51.36 \pm 1.29$ and in group B were $48.52 \pm$ $1.42,47.92 \pm 9.2,49.76 \pm 1.3,50.08 \pm 1.44$ respectively. $p$ value at 30 and 60 minutes were $>0.05$ and the groups were comparable. At 90 and 120 minutes the difference becomes significant with $p$ values being 0.001 and 0.04 , respectively.

In group $\mathrm{A}$ (Graph 8), the mean $\mathrm{Et}_{2} \mathrm{O}$ at $30 \mathrm{~min}, 60$ $\mathrm{min}, 90 \mathrm{~min}$ and $120 \mathrm{~min}$ were $45.88 \pm 2.01,48.8 \pm 1.88$, $50.15 \pm 1.49,50.45 \pm 1.13$ and in group B were $46.46 \pm 1.62$, $48.24 \pm 1.57,48.62 \pm 1.4,49 \pm 1.71$ respectively. $p$ values at 30 and 60 minutes are 0.12 and 0.11 . The difference is not significant. At 90 and 120 minutes $p$ is 0.001 and 0.023 thus the groups differ significantly.

\section{Comparison Within and Between Groups for Inspired (Ins $\left.\mathrm{CO}_{2}\right)$ and End-tidal Carbon Dioxide $\left(\right.$ Et $\left.\mathrm{CO}_{2}\right)$ Concentrations}

For each case, fresh soda lime was used. Normocapnoea was maintained by changing tidal volume and respiratory rate. In our study no patient observed any rise in inspired $\mathrm{CO}_{2}$.

\section{MAC Comparison Between Groups}

\section{Comparison of Time to Achieve MAC 0.8:}

The time taken to achieve the MAC value after intubation in both the groups was comparable by applying two sample $\mathrm{T}$ test (Table 3 ).

\section{Comparison of MAC Values in Both the Groups}

In group $A$, with vaporizer (Graph 9) setting of $5 \%$ the mean MAC at $30 \mathrm{~min}, 60 \mathrm{~min}, 90 \mathrm{~min}$ and $120 \mathrm{~min}$ were $1.02 \pm 0.11$, $1.1 \pm 0.11,1.13 \pm 0.11,1.15 \pm 0.11$ and in group B were $1.08 \pm 0.1,1.14 \pm 0.09,1.16 \pm 0.09,1.18 \pm 0.06$, respectively. The $p$ value at 30 and 60 minutes are 0.007 and 0.05 . Thus both the groups are significantly different at 30-60 minutes. At 90 and 120 minutes $p$ values are 0.44 and 0.46 . Hence 


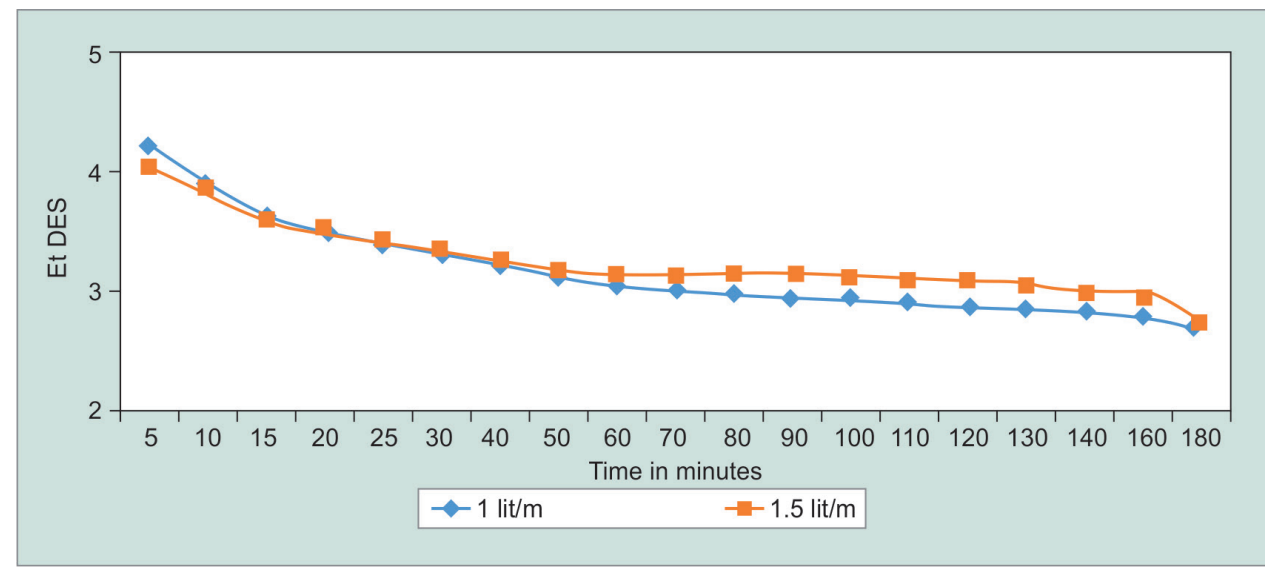

Graph 5: Inspired oxygen (Ins O2) in two groups

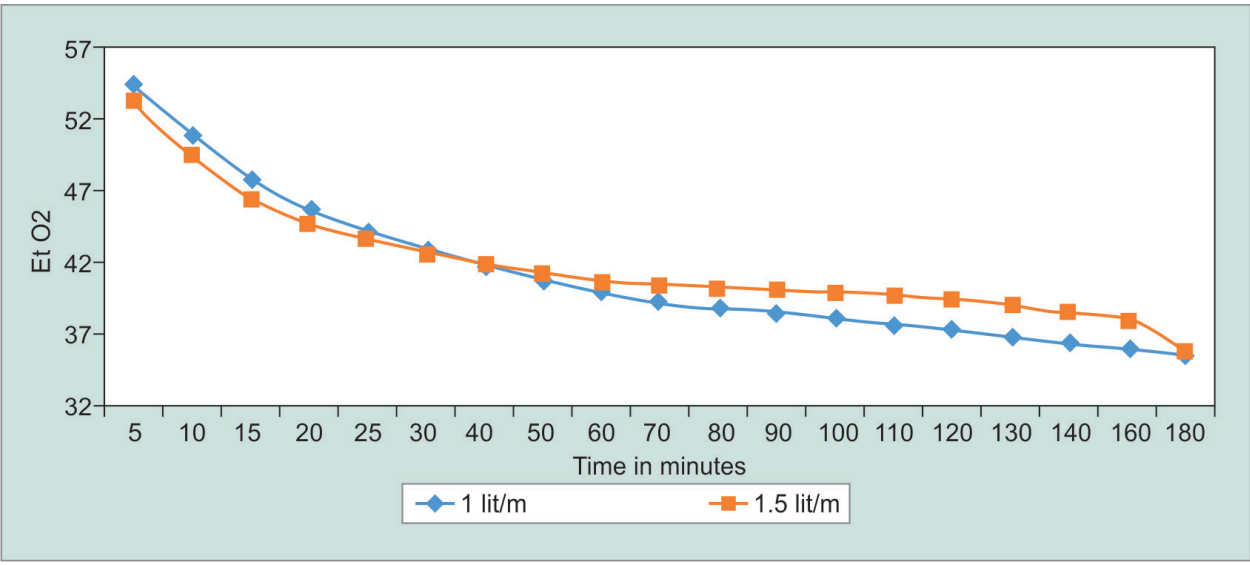

Graph 6: Et oxygen concentrations

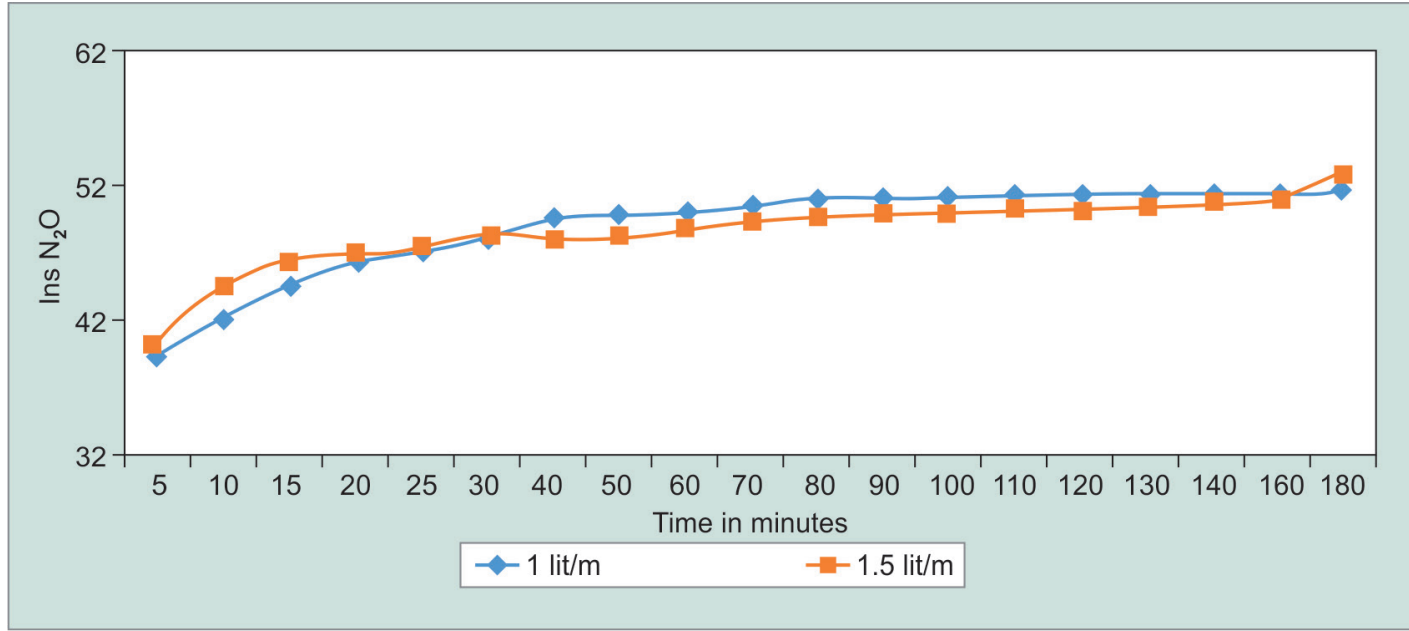

Graph 7: Ins $\mathrm{N}_{2} \mathrm{O}$ concentrations in the two groups

groups are comparable with respect to MAC values at 90-120 minutes.

\section{Comparison of Heart Rate between the Two Groups}

The preoperative mean HR (Graph 10) in group A was $83.94 \pm 12.88$ beats per minute and in group B was $79.88 \pm$ 13.45 beats per minute which are comparable in both the groups. The heart rates were comparable all throughout the surgery and post operatively at all point times except at intubation by two sample $\mathrm{T}$ test.

\section{Comparison of MAP in Two Groups}

The preoperative mean (SD) MAP (Graph 11) in Group A was $93.61 \pm 9.99 \mathrm{~mm} \mathrm{Hg}$ and in group B was $95.68 \pm 8.19$ $\mathrm{mm} \mathrm{Hg}$. The mean MAP was maintained in both groups and the values were comparable in both the groups at all times. 


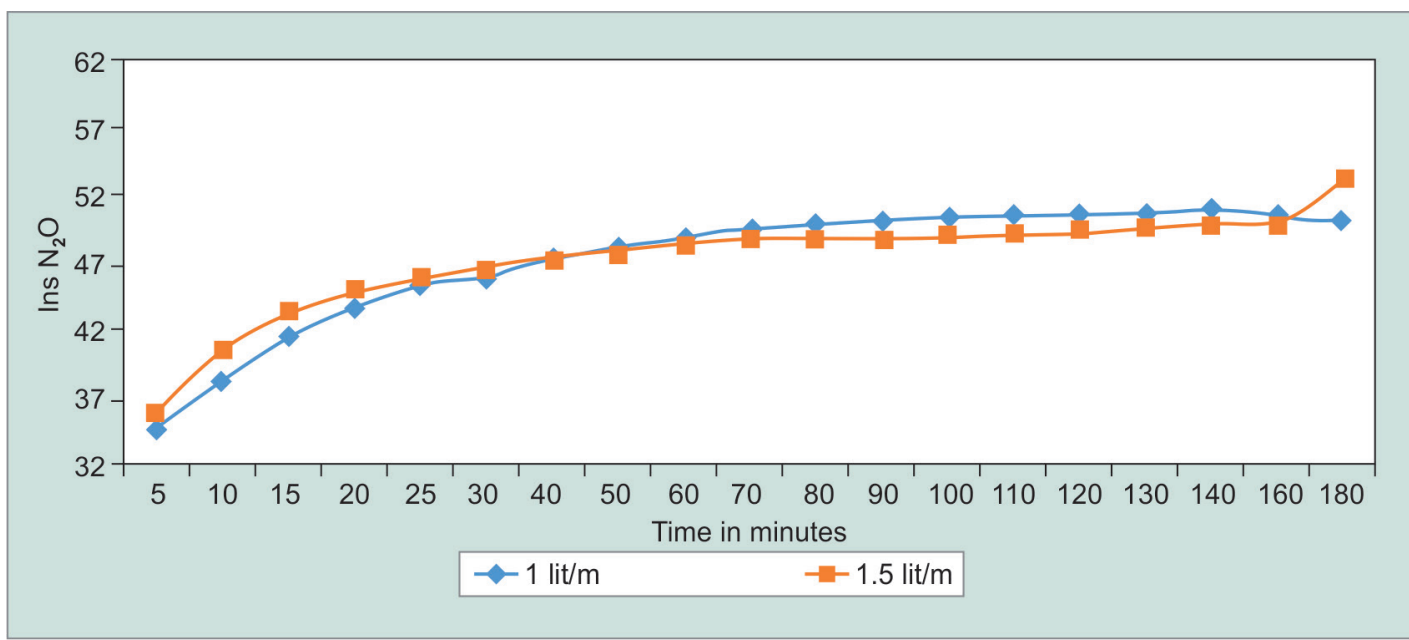

Graph 8: End tidal $\mathrm{N}_{2} \mathrm{O}$ concentrations in the two groups

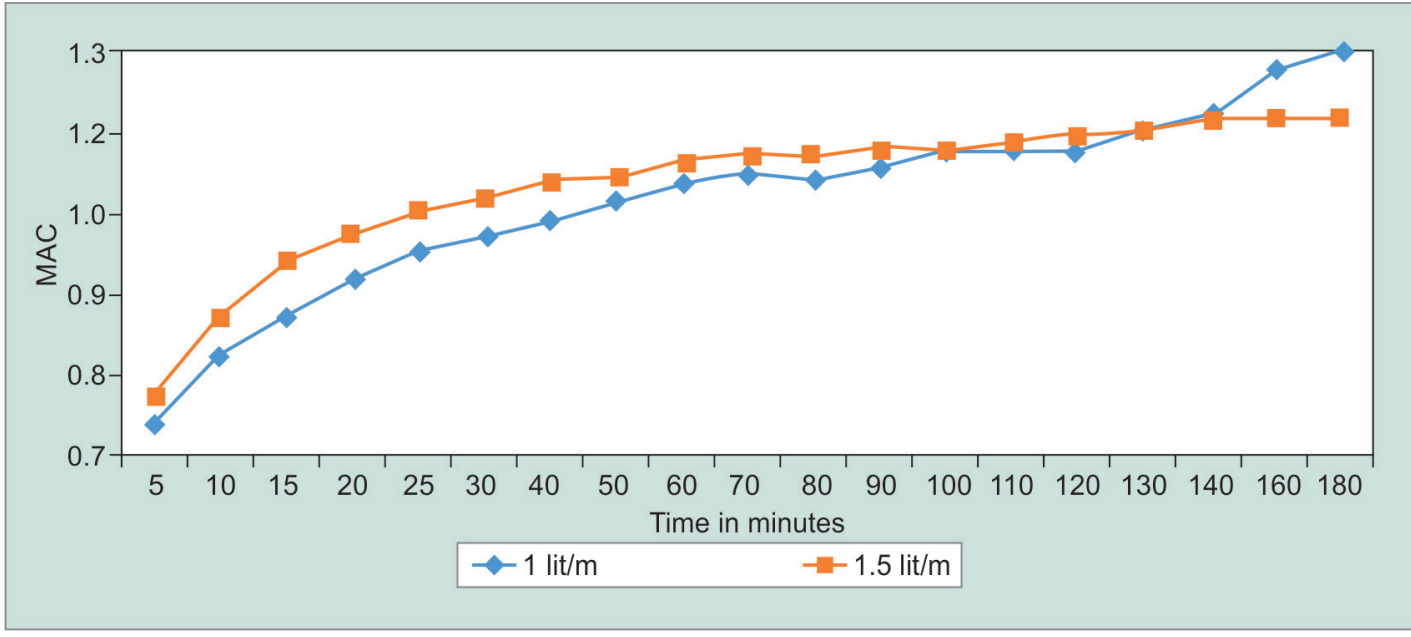

Graph 9: MAC values in the two groups

An entropy of 40-60 was achieved prior to intubation and was maintained throughout the surgery. The patient was extubated after achieving entropy more than 90 .

\section{Recovery Parameters}

The time required for recovery parameters (Table 4) were significantly lesser in the group A as compared to group B except for time required for spontaneous eye opening which were comparable by applying two sample $\mathrm{T}$ test.

\section{Comparison of Total Per Hour Requirements of Inhalational Gases and Fentanyl in Both the Groups}

The requirements were calculated by using one way ANOVA test (Table 5).

In group $\mathrm{A}$, average per hour requirement for Desflurane was found to be lesser $22.18 \mathrm{~mL} /$ hour than $29.21 \mathrm{~mL} /$ hour in group $\mathrm{B}, p$ value being $<0.0001$. The mean requirement per hour for $\mathrm{O}_{2}$ and $\mathrm{N}_{2} \mathrm{O}$ for Group A was higher than group $B, p$ value for both being $p<0.0001$. The average fentanyl requirement $/ \mathrm{kg} /$ hour were comparable $1.66 \mathrm{mcg} / \mathrm{kg} /$ hour in group A and 1.74 $\mathrm{mcg} / \mathrm{kg} /$ hour in group B, $p$ value being 0.118 .

\section{Comparison of Incidences of Postoperative Nausea and Postoperative Pain}

Table 6 shows the number of patients experiencing pain postoperatively. After applying two proportion test, $p$ value at $30 \mathrm{~min}$ is 0.56 and at 2 hour is 0.38 . Thus the difference is statistically not significant.

\section{Comparison of Averages of Postoperative Sedation}

The postoperative sedation scores (Table 7) were comparable in both the groups $p>0.05$.

\section{Incidence of Awareness}

None of our patients experienced awareness.

\section{DISCUSSION}

Desflurane is one of the newer anaesthetic agent which has very low blood and tissue solubility and has low blood/gas (0.42) and oil/gas (18.7) partition coefficients (1). This indicate that it will undergo rapid wash in and washout and thus rapid induction and recovery from anesthesia. It has a MAC value of about $6.6 \%(1,3)$. These properties make it suitable for a LFA. LFA apart from 


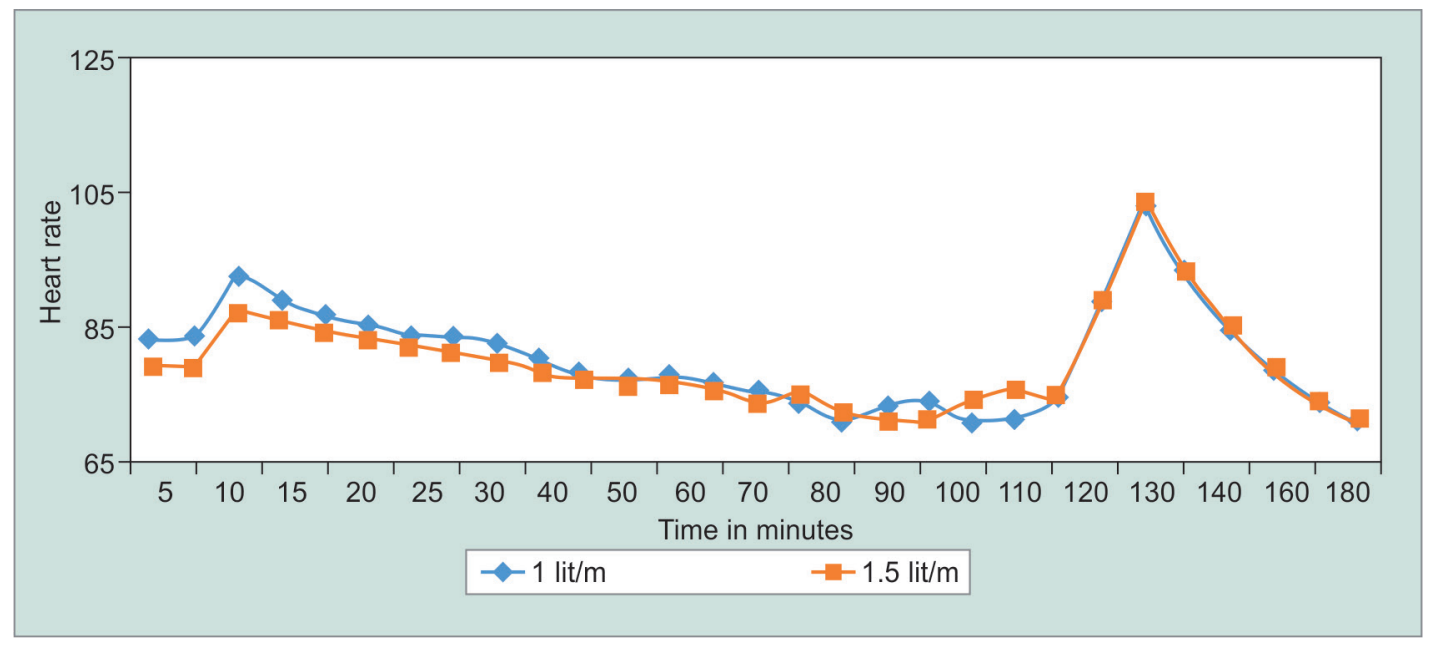

Graph 10: Heart rate in two groups

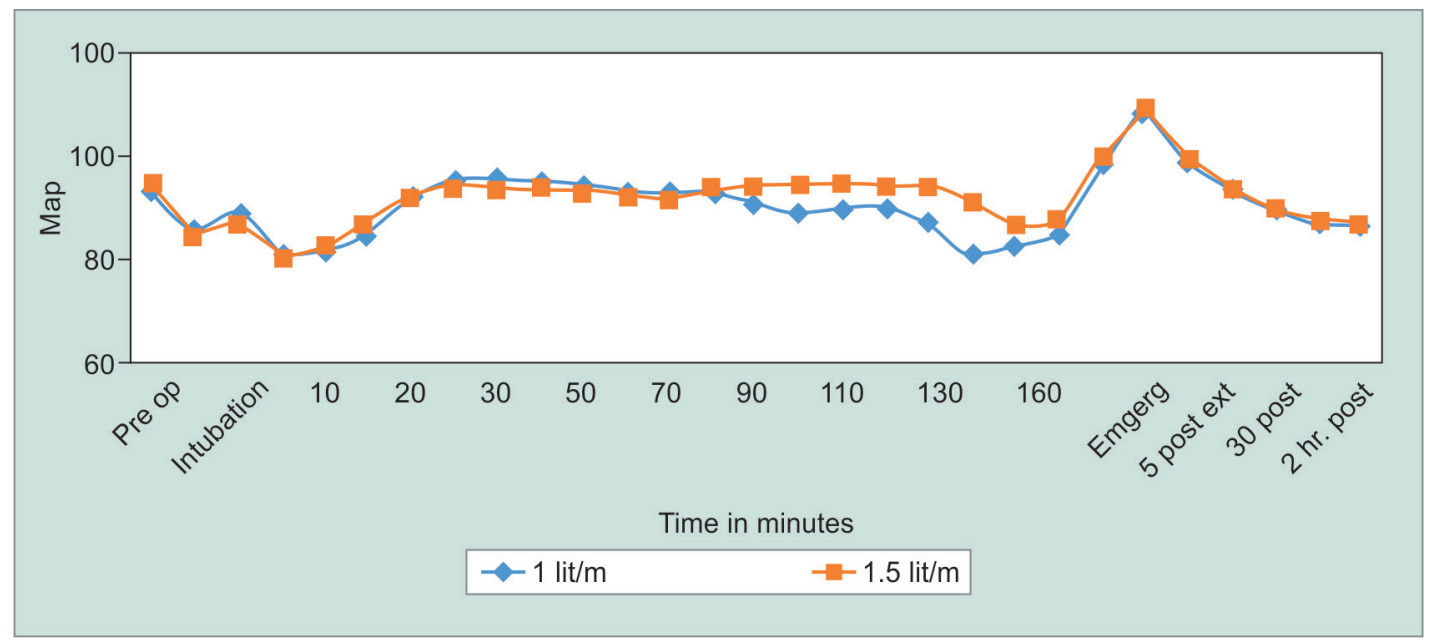

Graph 11: Mean arterial pressure in two groups

Table 3: Time to achieve MAC 0.8

\begin{tabular}{llllll}
\hline Variable & Group & Mean & St dev & Median & $p$ value \\
\hline T MAC & Group A & 143.22 & 40.66 & 134.5 & $p=0.522$ \\
$0.8(\mathrm{sec})$ & Group B & 138.6 & 30.5 & 134 & \\
\end{tabular}

being economical is very effective in maintaining the heat and humidity of inspired gases. It also serves as a measure to reduce environmental pollution. In today's modern era of advanced monitoring, LFA can be safely practiced while adding the advantages of desflurane.

We conducted the present study to determine the InsDes and EtDes concentrations at 1 and $1.5 \mathrm{~L} / \mathrm{min}$ FGF while maintaining hemodynamics and depth of anesthesia in Indian population. The cases were conducted on Avance machine by GE healthcare which has diverting (sidestream) system.

The present study included 100 patients of ASA grades I and II, of either sex undergoing laparoscopic abdominal and pelvic surgeries which included major proportion of gynecological surgeries. Both the groups comprised of 50 patients each. The vaporizer setting was fixed at $5 \%$ desflurane. We monitored the inspired and end tidal concentrations of $\mathrm{O}_{2}, \mathrm{~N}_{2} \mathrm{O}$ and $\mathrm{CO}_{2}$.
Table 4: Time required for recovery parameters

\begin{tabular}{|c|c|c|c|c|c|}
\hline \multirow{2}{*}{$\begin{array}{l}\text { Recovery } \\
\text { parameters }\end{array}$} & \multicolumn{2}{|c|}{ Group A } & \multicolumn{2}{|c|}{ Group B } & \multirow[b]{2}{*}{$p$ value } \\
\hline & Mean & $S D$ & Mean & $S D$ & \\
\hline $\begin{array}{l}\text { Time for } \\
\text { Decrease in } \\
\text { EtDes by } 50 \% \\
\text { (sec) }\end{array}$ & 74.62 & 21.26 & 85.38 & 28.7 & 0.036 \\
\hline $\begin{array}{l}\text { Time for } \\
\text { entropy } 80-90 \\
\text { (sec) }\end{array}$ & 270 & 94.4 & 312.2 & 123.3 & 0.057 \\
\hline $\begin{array}{l}\text { Time for } \\
\text { response } \\
\text { to verbal } \\
\text { commands } \\
\text { (sec) }\end{array}$ & 288.7 & 98.9 & 342.8 & 143.8 & 0.031 \\
\hline $\begin{array}{l}\text { Time for } \\
\text { spontaneous } \\
\text { eye opening } \\
\text { (sec) }\end{array}$ & 396.8 & 102.1 & 436.9 & 155.6 & 0.132 \\
\hline $\begin{array}{l}\text { Time for } \\
\text { extubation } \\
\text { (sec) }\end{array}$ & 424.5 & 108.8 & 482.5 & 162.5 & 0.039 \\
\hline
\end{tabular}

A similar study was done by Johansson et al. ${ }^{4}$ in 2001 to determine inspired and end tidal concentrations of desflurane at 1 and $2 \mathrm{~L} / \mathrm{min}$ fresh gas flow. They studied 
Table 5: Total per hour requirements of Des, $\mathrm{O}_{2}, \mathrm{~N}_{2} \mathrm{O}$ and fentanyl

\begin{tabular}{llll}
\hline $\begin{array}{l}\text { Per hour } \\
\text { requirement }\end{array}$ & Group A & Group $B$ & $p$ value \\
\hline Desflurane $(\mathrm{mL})$ & 22.18 & 29.21 & $p<0.001$ \\
$\mathrm{O}_{2}$ (lit) & 47.94 & 65.184 & $p<0.001$ \\
$\mathrm{~N}_{2} \mathrm{O}$ (lit) & 32.66 & 45.28 & $p<0.001$ \\
$\begin{array}{l}\text { Fentanyl (per kg } \\
\text { per hour mcg) }\end{array}$ & 1.66 & 1.74 & 0.118 \\
\hline
\end{tabular}

Table 7: Averages of postoperative sedation scores

\begin{tabular}{llll}
\hline Postoperative sedation & Group A & Group B & $p$ value \\
\hline 5 minutes & 2.14 & 2.16 & 0.203 \\
15 minutes & 2.04 & 2.04 & 0.774 \\
30 minutes & 2 & 2 & - \\
1 hour & 2 & 2 & - \\
2 hour & 2 & 2 & - \\
\hline
\end{tabular}

56 patients (28 patients in each group) scheduled for elective surgery of an expected anaesthesia time of at least $120 \mathrm{~min}$. The InsDes and EtDes concentrations were measured during LFA with FGF of 1.0 and $2.0 \mathrm{~L}$ $\min -1$. The vaporizer setting was fixed at $5 \%$ Desflurane. We decided to conduct this study and evaluate the pharmacokinetics of desflurane at 1 and $1.5 \mathrm{~L} / \mathrm{min}$ FGF, measure the safety as per the oxygenation and depth of anesthesia as there was no such data available for the Indian population.

Patients fulfilling the inclusion criteria were allotted to respective groups. After intubation the FGF was set at $4 \mathrm{~L} / \mathrm{min}$ with oxygen: nitrous oxide ratio of $50: 50$ and Desflurane vaporizer setting at $5 \%$.

Mapleson et al. ${ }^{5}$ in his study on ideal FGF sequence at the start of LFA concluded that, with FGF set initially equal to the total ventilation and the fresh gas partial pressure to $3 \mathrm{MAC}$, the end expired partial pressure can be raised to $1 \mathrm{MAC}$ in one minute with desflurane.

Borges et al. ${ }^{6}$ studied the theoretical model of Mapleson, the FGF sequence at the start of LFA with different inhalational agents in 28 patients of both genders, aged $18-55$ years. They used initial FGF of 3.5 $\mathrm{L} / \mathrm{min}$ for $1 \mathrm{~min}$ and $1 \mathrm{lit} / \mathrm{min}$ upto the 20th minute for Desflurane. They concluded the clinical feasibility of Mapleson's theoretical model. This way, a fast FA increase of the inhaled agent was achieved, which reached 1 MAC in 1-2 minutes and was maintained within this value with LFA, with minor variations and low anesthetic consumption.

Hence we decided on to an initial fresh gas flow of $4 \mathrm{~L} / \mathrm{min}$ followed by 1 or 1.5 litre/min.

Baum et al. ${ }^{7}$ conducted this clinical investigation for the development of a standardised dosing scheme for low-flow and minimal-flow desflurane anesthesia.
Table 6: Incidences of postoperative nausea and postoperative pain

\begin{tabular}{lllll}
\hline & \multicolumn{2}{c}{ Postoperative pain } & \multicolumn{2}{c}{ Postoperative nausea } \\
\cline { 2 - 5 } Group & 30 Min & 2 HR & Count & $\begin{array}{l}\text { \% of postoperative } \\
\text { nausea }\end{array}$ \\
\hline A & 1 & 17 & 7 & 14 \\
B & 2 & 13 & 9 & 18 \\
\hline
\end{tabular}

One hundred six ASA status I-II patient after an initial high FGF phase using $4.4 \mathrm{~L} / \mathrm{min}$, the FGF were reduced to $0.5 \mathrm{~L} /$ minute or $1 \mathrm{~L} /$ minute. InsDes concentrations were applied in the range from $3.4-8.7 \%$. They found that if the FGF is reduced to $1 \mathrm{~L} /$ minute, the InsDes concentration achieved in initial high FGF phase can be maintained without any alteration of vaporizer setting.

Nickalls et al. ${ }^{3}$ studied the age related iso-MAC charts for isoflurane, sevoflurane and desflurane. As per the Iso MAC chart for desflurane described by them, we decided to decrease the FGF after attaining MAC of 0.8.

\section{Demographic Characteristics of the Patients}

The age and sex distribution in (Table 1) groups A and $\mathrm{B}$ were comparable. Group A had 10\% males and group B had $22 \%$ males. The female population was greater as most of our cases were gynecologic laparoscopic procedures. The mean weight and height in both groups were comparable. Both the groups were comparable with respect to ASA distribution. Both the groups had 54\% ASA1 and $46 \%$ ASA2 patients. The mean duration of anesthesia for group A was $98.06 \pm 31.08$ and for group B was $92.9 \pm 32.02$ which was also comparable.

\section{Comparison of Inspired and End-tidal Desflurane Concentrations}

In our study, it was found that InsDes and EtDes concentrations (Graphs 1 and 2) were significantly different in both the groups.

With a vaporizer setting of $5 \%$, the InsDes concentrations in group A at 30, 60, 90 and 120 min were $4.05 \pm 0.21,4.22 \pm 0.18,4.25 \pm 0.13,4.28 \pm 0.12$ and $4.22 \pm 0.19$, $4.33 \pm 0.17,4.38 \pm 0.14,4.42 \pm 0.11$ for group $B$, respectively. The $p$ values are $<0.05$ at $30(p=0.0001), 60(p=0.003), 90$ $(p=0.002)$ and $120(p=0.008)$ minutes. Thus groups differ significantly, being higher in group $B$.

In group A, EtDes concentrations were $3.64 \pm 0.25$, $3.89 \pm 0.22,3.99 \pm 0.16,4.05 \pm 0.14$ and $3.81 \pm 0.22$, $4 \pm 0.2,4.09 \pm 0.17,4.15 \pm 0.15$ for $1.5 \mathrm{~L} / \mathrm{min}$, respectively. The $p$ values are $<0.05$ at 30,60 and 90 minutes $(0.0001$, $0.011,0.05$, respectively) but is $>0.05$ (0.09) at 120 minutes. Thus it is found that though both the groups differ significantly at 30, 60 and 90 minutes, they are comparable 
at 120 minutes which means that as time increases there is equilibrium achieved between InsDes and EtDes concentrations.

As per Johansson et al., ${ }^{4}$ with a vaporizer setting of $5 \%$, the InsDes and EtDes concentrations in the $1.0 \mathrm{~L} /$ min group after $120 \mathrm{~min}$ were $4.54 \%$ vs. $4.37 \%$. In the 2.0 $\mathrm{L} / \mathrm{min}$ group, the InsDes and EtDes concentrations were $4.76 \%$ vs. $4.58 \%$. $p$ was $<0.001$ for both the groups.

\section{Comparison of Difference between InsDesflurane and End-tidal Desflurane and End-tidal to Inspired Concentration Ratio}

The differences in the InsDes and EtDes concentration (Table 2) and the ratio of EtDes concentration to InsDes concentration (Graph 3) represent the degree of uptake and saturation of desflurane with a fixed inspired concentration. In the present study, with dial concentration of $5 \%$ the difference between InsDes and EtDes in group A at 30, 60, 90 and 120 min were $0.41,0.33,0.26$ and 0.23 . Same for group B were $0.41,0.33,0.29$ and 0.27 . The difference in two groups is not found to be significant at 120 minutes ( $p=0.54$ ). The difference goes on decreasing with increasing level of saturation.

Johansson et al. ${ }^{4}$ found that the estimated difference between inspired and end-tidal values, at $120 \mathrm{~min}$ of anaesthesia, were $0.17 \%$ in the $1.0 \mathrm{~L} /$ minute group as compared to $0.18 \%$ in the $2.0 \mathrm{~L} /$ minute group which was not significant.

On calculation of the mean end tidal/ inspired concentration ratio, it was found to be 0.91 in both group A and group B in our patients. The EtDes/InsDes concentration ratio increased from 0.78 in both groups at 5 mins to 0.95 in group A and 0.98 in group B, the values being comparable. It means as the duration of anaesthesia progresses the equilibrium is achieved.

While Johansson et al. ${ }^{4}$ found that in their study population, ratio of end-tidal/inspired concentration was 0.96 in both groups. Jones et al. ${ }^{8}$ also conducted a similar study where the ratio was 0.82 . Yasuda et al. ${ }^{9}$ found that ratio of inspired to end tidal concentrations for Desflurane increases more rapidly than for isoflurane and halothane. At 30 minute it was $0.9 \pm 0.01$.

\section{Comparison of Ratio of End-tidal Concentration/ Vaporizer Setting}

We found that mean values for ratio of EtDes concentration to vaporizer setting at $5 \%$ (Graph 4 ) in group A at $30 \mathrm{~min}$ was 0.7284 and 0.81 at 180 minutes. For group B, the ratios at 30 mins was 0.7628 and 0.86 at 180 mins, the difference between both the groups was not significant. It was observed that the ratio is increasing with increasing duration of anesthesia. This indicates that saturation level goes on increasing with time and by increasing the fresh gas flow from 1-1.5 litres the increase in end tidal concentration is just 0.05 after 180 mins.

Johansson et al. ${ }^{4}$ found that at $120 \mathrm{~min}$ the ratio endtidal concentration/vaporizer setting was 0.87 in the 1.0 $\mathrm{L} /$ min group vs. 0.92 in the $2.0 \mathrm{~L} /$ minute group.

Thus it was found that, though there was a significant difference between InsDes and EtDes concentrations at 1 and $1.5 \mathrm{~L} /$ minute $\mathrm{FGF}$, the ratio of InsDes to EtDes was same in both the groups. Similarly Johansson et al. ${ }^{4}$ found that there was a significant difference between 1.0 and $2.0 \mathrm{~L} /$ minute for InsDes and EtDes but not for the ratio of inspired to end tidal concentration.

\section{Comparison of Inspired and End Tidal Oxygen Concentrations}

We found that there was a significant difference in $\mathrm{InsO}_{2}$ (Graph 5) as well as $\mathrm{EtO}_{2}$ (Graph 6) concentrations in both the groups. For $\mathrm{InsO}_{2}$ concentration at 30 minutes, $p$ value was 0.64 and the groups are comparable. At 60, 90 and 120 minutes $p$ values are $<0.05$ (0.0001). Thus groups differ significantly in $\mathrm{Ins}_{2}$ levels.

Inspite of this significant decrease in inspired concentrations of $\mathrm{O}_{2}$, the mean values in Group A at 30 $\mathrm{min}, 60 \mathrm{~min}, 90 \mathrm{~min}$ and $120 \mathrm{~min}$ were $45.24 \pm 1.49,43 \pm$ $1.21,41.77 \pm 0.99,40.91 \pm 1.14$ and in Group B were 45.36 $\pm 1.03,43.8 \pm 0.99,43.33 \pm 1.15,43.08 \pm 1$ respectively.

In group $\mathrm{A}$, the mean $\mathrm{EtO}_{2}$ concentration at $30 \mathrm{~min}$, $60 \mathrm{~min}, 90 \mathrm{~min}$ and $120 \mathrm{~min}$ were $42.98 \pm 1.93,39.86 \pm 1.69$, $38.31 \pm 1.23,37.09 \pm 1.3$ and in group $B$ were $42.7 \pm 1.45$, $40.72 \pm 1.16,39.95 \pm 1.07,39.5 \pm 1$, respectively. $p$ value is 0.41 at 30 minutes. Thus there is no significant difference in end tidal oxygen levels in both the groups. But at 60, 90 and 120 minutes $p<0.05$ (0.004, 0.0001 and 0.0001$)$ and the groups differ significantly. Inspite of this significant difference in inspired and end-tidal oxygen concentrations, adequately safe levels oxygen concentrations were maintained during the anesthesia.

\section{Comparison of Inspired and End-tidal Nitrous Oxide Concentrations}

It was found that $\mathrm{InsN}_{2} \mathrm{O}$ (Graph 7) varies with respect to time in both the groups but when we compare the Ins $\mathrm{N}_{2} \mathrm{O}$ in both the groups, it was found that the mean Ins $\mathrm{N}_{2} \mathrm{O}$ concentration in group A at $30 \mathrm{~min}, 60 \mathrm{~min}, 90$ $\min$ and $120 \mathrm{~min}$ were $48.06 \pm 1.81,50.32 \pm 1.53,51.19 \pm$ $1.55,51.36 \pm 1.29$ and in group B were $48.52 \pm 1.42,47.92$ $\pm 9.2,49.76 \pm 1.3,50.08 \pm 1.44$ respectively. $p$ values at 30 and 60 minutes are $>0.05$ and the groups are comparable. At 90 and 120 minutes the difference becomes significant with $p$ values being 0.001 and 0.04 , respectively. 
Similarly, in group A, the mean $\mathrm{EtN}_{2} \mathrm{O}$ concentration (Graph 8) at $30 \mathrm{~min}, 60 \mathrm{~min}, 90 \mathrm{~min}$ and $120 \mathrm{~min}$ were $45.88 \pm 2.01,48.8 \pm 1.88,50.15 \pm 1.49,50.45 \pm 1.13$ and in group B were $46.46 \pm 1.62,48.24 \pm 1.57,48.62 \pm 1.4,49 \pm$ 1.71 respectively. $p$ values at 30 and 60 minutes are 0.12 and 0.11 . The difference is not significant. At 90 and 120 minutes $p$ value is 0.001 and 0.023 respectively, thus the groups differ significantly.

Yasuda et al. ${ }^{9}$ found that the mean value for ratio of end tidal to inspired concentration of $\mathrm{N}_{2} \mathrm{O}$ at $30 \mathrm{~min}$ was $0.99 \pm 0.01$.

\section{Comparison of Inspired and End-tidal Carbon Dioxide Concentrations}

For each case, fresh soda lime was used. Normocapnoea was maintained by changing tidal volume and respiratory rate. In our study no patient observed any rise in inspired $\mathrm{CO}_{2}$. Et $\mathrm{CO}_{2}$ values for two groups were comparable.

\section{Comparison of MAC}

Weassessed the timerequired to achieveMAC of 0.8 (Table3) was $143.22 \pm 40.66$ seconds after starting Desflurane in group A and $138.6 \pm 30.5$ seconds in group B. As $p=0.522$, there is no significant difference between the groups. Borges et al. ${ }^{7}$ foundthat in seven patients studied for EtDes concentrations reached 0.94 MAC in 1 minute and varied from 1.07-1.14 until the 20th min. Quenet et al. ${ }^{10}$ found that they could achieve EtDes concentrations required to get $1 \mathrm{MAC}$ within $2.1 \pm 0.9 \mathrm{~min}$ with low FGF (1 litre) with delivered concentration at maximal value on vaporizer and then set to $20 \%$ above target end tidal value.

In group $\mathrm{A}$, with vaporizer setting of $5 \%$ (Graph 9), the mean MAC at $30 \mathrm{~min}, 60 \mathrm{~min}, 90 \mathrm{~min}$ and $120 \mathrm{~min}$ were 1.02 $\pm 0.11,1.1 \pm 0.11,1.13 \pm 0.11,1.15 \pm 0.11$ and in group $B$ were $1.08 \pm 0.1,1.14 \pm 0.09,1.16 \pm 0.09,1.18 \pm 0.06$, respectively. $p$ values at 30 and 60 minutes are 0.007 and 0.05 .Thus groups are statistically significantly till 60 minutes. It means as the duration of anesthesia increases at different flow rates, MAC values become comparable as saturation is achieved.

\section{Hemodynamic Parameters}

\section{Heart Rate}

The mean preoperative HR (Graph 10) in group A was $83.94 \pm 12.88$ per minute and in group $B$ was $79.88 \pm 13.45$ per minute, $p=0.13$. Thus the two groups were comparable. The HR were comparable at all time points during the surgery, during emergence and post operatively except during the time of intubation.

At the time of intubation mean HR in group A was $94 \pm 11.74$ per minute and in group $B$ was $88.54 \pm 14$. 48 beats per minute $p=0.04$. Thus the difference was significant.

\section{Blood Pressure}

The preoperative mean SBP (Graph 11) in group A was $129.84 \pm 15.47 \mathrm{~mm} \mathrm{Hg}$ and in group $B$ was $130.68 \pm 12.87$ $\mathrm{mm} \mathrm{Hg}$. $p$ value was 0.77 . The preoperative mean DBP in group A was $75.5 \pm 8.27 \mathrm{~mm} \mathrm{Hg}$ and in group B was $78.18 \pm 7.3 \mathrm{~mm} \mathrm{Hg}, p$ value being 0.09$)$. The mean MAP in group A was $93.61 \pm 9.99 \mathrm{~mm} \mathrm{Hg}$ and in group B was $95.68 \pm 8.19 \mathrm{~mm} \mathrm{Hg}, p$ value 0.26 . The mean SBP, DBP and MAP were comparable at all time points during the surgery, during emergence and postoperatively.

The higher values were found at the time of induction, intubation, emergence and extubation. There is also a rise in MAP values around 20 mins of starting Desflurane which coincides with $\mathrm{CO}_{2}$ insufflations.

Additional doses of $25 \mathrm{mcg}$ of fentanyl were administered if MAP increased more than $20 \%$ of baseline and a similar decrease in pressure was set to be treated with iv fluids and then Inj ephedrine though none of our patients required ephedrine.

Xie et al. ${ }^{11}$ compared the hemodynamic effects during low flow anesthesia with Desflurane, sevoflurane and Enflurane. They found that desflurane caused least cardiovascular depression with MAP maintained significantly better than other two agents and HR was stabilized earlier post incision.

\section{Comparison of Entropy in Both the Groups}

Entropy levels were monitored in each patient to ensure the depth of anesthesia. The entropy was maintained between 40-60 all throughout the surgery.

\section{Comparison of Time Required for Decrease in EtDes by $50 \%$}

The mean time required for decrease in EtDes by $50 \%$ (Table 4) in group A was $74.62 \pm 21.26$ seconds as compared to $85.38 \pm 28.7$ seconds in group B. These values are found to be statistically significant $(p=0.036)$.

Jones et $a .^{8}$ studied desflurane for induction and recovery time in 10 ASA 1 patients. As per him, $10 \mathrm{~min}$ after discontinuing administration of desflurane, the end tidal concentration relative to the last concentration during administration of anaesthetic was 0.11 and alveolar concentrations (determined by end tidal concentration) decreased by $90 \%$ after $10-15$ min of wash out.

Ghouri et al. ${ }^{12}$ studied the recovery profile of desflurane which shows that time required for the end-tidal concentration to decrease by $50 \%$ was $2.5 \pm 0.8$ minute.

\section{Comparison of Time to Achieve Entropy of 80-90}

The mean time required for entropy to reach 80-90 after stopping desflurane was $270 \pm 94.4 \mathrm{sec}$ for group A and $312.2 \pm 123.3$ seconds for group B which was statistically 
comparable $p$ value being 0.057 . It signifies that the time at which patient became arousable were similar in both the groups.

\section{Comparison of Time Required for Recovery After Stopping Desflurane}

The mean time required for response to verbal commands was found to be $288.7 \pm 98.9 \mathrm{sec}$ in group A as compared to $342.8 \pm 143.8$ seconds for group B. This difference was statistically significant $(p=0.031)$. Jones et al..$^{8}$ found in their study that volunteers responded to commands at an average of $2.7 \mathrm{~min}$ after discontinuing anesthetic administration. Ghouri et al. ${ }^{12}$ found that time for awakening and ability to follow simple commands were significantly shorter for desflurane than for isoflurane. For desflurane average time was $5.1 \pm 2.4$ and $6.5 \pm 2.3$ minutes.

The mean time required for spontaneous eye opening was $396.8 \pm 102.1$ and $436.9 \pm 155.6$ seconds for group A and group B, respectively and the difference was not significant $(p=0.132)$.

The mean time for extubation was $424.5 \pm 108.8$ seconds for group A and $482.5 \pm 162.5$ seconds for group $B$ and the difference was statistically significant with $p$ value being 0.039 .

\section{Comparison of Total Desflurane, Oxygen and Nitrous Oxide Requirement}

The mean total desflurane per hour requirement was $22.18 \mathrm{~mL}$ for group A and $29.21 \mathrm{~mL}$ for group B. This difference was statistically significant $(p \leq 0.0001)$. and thus requirement of desflurane is significantly reduced with 1 liter flow rate. Quenet et al. ${ }^{10}$ observed that volatile consumption was reduced by $75 \%$ in low fresh gas flows.

The mean nitrous oxide requirement per hour was 32.66 litre/hour for group A and 45.28 litre/hour for group B. This difference was statistically significant $(p \leq 0.0001)$.

The mean oxygen requirement per hour was 47.94 lit for group A and 65.184 lit for group B. This difference was statistically significant $(p \leq 0.0001)$.

\section{Comparison of Total Fentanyl per Hour per kilogram Requirement in Both the Groups}

The mean fentanyl requirement per kg per hour (Table 5) was $1.66 \mathrm{mcg}$ for group A and $1.74 \mathrm{mcg}$ for group B. This difference was statistically not significant $(p=0.118)$.

\section{Comparison of Postoperative Pain in both Groups}

It was assessed as per visual analogue scale from 0-10 where 0 being no pain at all and 10 being the intense unbearable pain. At 30 min postoperatively (Table 7), in group A $2 \%$ patients experienced pain, and $4 \%$ in group B. The difference was statistically not significant $(p=0.56)$. At $120 \mathrm{~min}$ postoperatively, in group A $34 \%$ patients experienced pain and $26 \%$ in group B. The difference was statistically not significant $(p=0.38)$.

Ghouri et al. ${ }^{12}$ observed that patients receiving Desflurane experienced significantly less discomfort as compared to isoflurane.

\section{Comparison of Postoperative Nausea and Sedation}

In group A 14\% patients and in group B 18\% patients experienced nausea (Table 6) and the differences are comparable $(p=0.38)$

The postoperative sedation was assessed by Ramsay sedation score (Table 6). The differences in postoperative sedation levels were not significant. Ghouri et al. ${ }^{12}$ also found that desflurane is associated with less postoperative drowsiness, fatigue, clumsiness and confusion.

\section{Comparison of Awareness in Both Groups}

None of the patients experienced awareness during anesthesia. They were questioned regarding awareness on the morning after the surgery.

\section{CLINICAL SIGNIFICANCE}

Desflurane can be used efficiently at lower rates with the advantage of reducing the cost and not jeopardising the safety as per the oxygenation, haemodynamic stability and depth of anesthesia.

\section{CONCLUSION}

After conducting this study, we conclude that pharmacokinetics of desflurane favour the use of low flow anesthesia. Safe administration of low flow anesthesia can be ensured by current practice of anesthesia and integrated monitoring with continuous and comprehensive analysis of inspiratory and expiratory gases. Conducting anesthesia at a FGF $1 \mathrm{~L} / \mathrm{min}$ was equally safe and there was no added advantage of using $1.5 \mathrm{~L} / \mathrm{min}$ FGF. In today's modern era low flow anesthesia can be safely practiced and reduces the cost and environmental pollution.

\section{REFERENCES}

1. Stoelting RK, Hillier SC. Pharmacology \& Physiology in Anaesthesia Practice. 4th edition. Philadelphia: Lippincott Williams \& Wilkins; 2006. Chapter 2, Inhaled Anesthetics, 42-82.

2. Editorial: Desflurane- the dawn of new era? Can J Anaesth1991; 38: 954-957.

3. Nickalls RW, Mapleson WW. Age-related iso-MAC charts for isoflurane, sevoflurane and Desflurane in man. Br J Anaesth. 2003;91:170-174. 
4. Johansson A, Lundberg D, Luttropp HH. Low flow anaesthesia with Desflurane: Kinetics during clinical procedures. Eur J Anaesthesiol 2001;18:499-504.

5. Mapleson WW. The theoretical ideal fresh gas flow sequence at the start of low flow anaesthesia. Anaesthesia 1998;53:264-272.

6. Borges MM, Saraiva RA. Fresh-gas flow sequence at the start of low-flow anesthesia: clinical application of Maplesons theoretical study. Rev Bras Anestesiol 2002;52:146-155.

7. Baum J, Berghoff M, Stanke HG, et al. Low-flow anesthesia with Desflurane. Anaesthesist 1997;46:287-293.

8. Jones RM, Cashman JN, Eger EI. II, et al. Kinetics and potency of Desflurane in volunteers. Anesth Analg 1990;70:3-7.
9. Yasuda N, Lockhart SH, Weiskopf RB, et al. Kinetics of desflurane, isoflurane, and halothane in humans. Anesthesiology 1991;74:489-498.

10. Quénet E, Weil G. Which settings to optimize anaesthetics delivery: fresh gas flow or delivered fraction? Ann Fr Anesth Reanim 2008;27:900-908.

11. Xie G. Clinical study of Desflurane on low flow anesthesia compared with sevoflurane and Enflurane. Chin Med J (Engl) 1997;110:707-710.

12. Ghouri AF, Bodner M, White PF. Recovery profile after Desflurane-nitrous oxide versus isoflurane-nitrous oxide in outpatients. Anesthesiology 1991;74:419-424. 